\title{
Article \\ Sensorless Control Strategy of a Permanent Magnet Synchronous Motor Based on an Improved Sliding Mode Observer
}

\author{
Wengen Gao ${ }^{1, * \mathbb{D}}$, Gang Zhang ${ }^{1}$, Mengxun Hang ${ }^{2}$, Sirui Cheng ${ }^{1}$ and Pengfei Li ${ }^{1}$ \\ 1 Key Laboratory of Advanced Perception and Intelligent Control of High-End Equipment, Ministry of \\ Education, Anhui Polytechnic University, Wuhu 241000, China; zg15755336267@gmail.com (G.Z.); \\ kesheng40@gmail.com (S.C.); pengfeili978@gmail.com (P.L.) \\ 2 Chery New Energy Automobile Co., Ltd., Wuhu 241002, China; hangmengxun@mychery.com \\ * Correspondence: ahpuchina@ahpu.edu.cn
}

Citation: Gao, W.; Zhang, G.; Hang,

M.; Cheng, S.; Li, P. Sensorless

Control Strategy of a Permanent

Magnet Synchronous Motor Based on an Improved Sliding Mode Observer. World Electr. Veh. J. 2021, 12, 74

https://doi.org/10.3390/wevj12020074

Academic Editors: Joeri Van Mierlo and Zi-Qiang Zhu

Received: 24 February 2021

Accepted: 6 May 2021

Published: 10 May 2021

Publisher's Note: MDPI stays neutral with regard to jurisdictional claims in published maps and institutional affiliations.

Copyright: (c) 2021 by the authors. Licensee MDPI, Basel, Switzerland. This article is an open access article distributed under the terms and conditions of the Creative Commons Attribution (CC BY) license (https:// creativecommons.org/licenses/by/ $4.0 /)$.

\begin{abstract}
This paper analyzes the problems and the reasons of high frequency chattering, phase delay, unmanageable with low-speed rotation in the traditional SMO control strategy of the sensor-less control strategy of a permanent magnet synchronous motor based on the traditional sliding mode observer. Aiming at the shortcomings of the above-mentioned traditional SMO control strategy, an improved SMO control strategy is presented by replacing the signum function in the traditional synovial observer with the sigmoid function to reduce the high frequency chattering of the system. Meanwhile, the proposed improved SMO control strategy introduces an adaptive filter to eliminate harmonics and chattering, and adaptively compensates the estimated back-EMF value to reduce the estimation error caused by the phase delay. The improved SMO strategy was tested through Matlab/Simulink simulation and real experiments respectively. The results verified that the improved SMO strategy can significantly reduce chattering and phase delay and achieve good control performance at low speeds, as well as maintain good performance at full speed.
\end{abstract}

Keywords: permanent magnet synchronous motor; sliding mode observer; sigmoid function; adaptive filter; position estimation

\section{Introduction}

In 2019, China's car ownership ranked first in the world and the greenhouse effect, environmental pollution and other problems became apparent. Therefore, in recent years, a new energy industry has been vigorously developed, with electric vehicles foremost [1] Because of its small size, high stability, simple structure and high-power density, the permanent magnet synchronous motor has become the main driving force of electric vehicles [2]. However, traditional PMSM control needs to rely on photoelectric encoders, resolvers, and other components to extract the speed and position information of the motor rotor. These sensors not only increase the economic cost and installation difficulty, but also are susceptible to interference from the external environment causing detection errors, which is related to accidents and affects the safety performance of the vehicle $[3,4]$. Therefore, the research of sensor-less PMSM control strategy is of great significance.

The sensor-less control strategy extracts the PMSM voltage, current, and back-EMF signals, and then estimates the motor's speed and rotor position information through different mathematical models. There are currently three main estimation methods, which are divided into low-speed, high-speed, and full-speed sections according to the operating speed of the motor [4]. When the motor rotor speed is low or even zero speed, the back-EMF signal is weak and is accompanied by many interference signals, which are difficult to accurately detect. Then, the speed and position of the motor rotor are generally estimated by using the salient pole characteristics of the motor [5] and injecting additional 
high-frequency signals. The commonly used methods include the rotating high frequency voltage injection method [6,7], and the pulsed high frequency voltage injection method [8,9]. When the motor is running in the high-speed range, the back-EMF signal enhancement and extraction are simple. Then, a control strategy based on a fundamental mathematical model is usually used [4], which includes the synovial observer algorithm [10-15], the model reference adaptive algorithm [16,17], the extended Kalman filter algorithm [18,19], etc. For observation at full speed, most of the hybrid control strategies are currently used,. combining two different estimation strategies of low-speed section and high-speed section to observe the motor speed and rotor position respectively. For the transition area between low speed and high speed, the linear weighted average algorithm [20] is employed.

The traditional SMO observer algorithm is robust and insensitive to external disturbances. However, in the traditional SMO algorithm, a sign function as the switching function of the system cause shigh-frequency chattering, and a phase delay occurs due to a low-pass filter with a fixed cut-off frequency to extract the discrete back-EMF signal. This article provides an improved new SMO control strategy by using a sigmoid function to replace the signum function in the traditional SMO in order to reduce the high frequency chattering of the system, and to introduce an adaptive filter instead of a low-pass filter with a fixed cutoff frequency to further eliminate harmonics and chattering. Meanwhile the proposed SMO algorithm adaptively compensates the estimated back EMF and reduces the estimation error caused by the phase delay. Through Matlab/Simulink simulation analysis and experimental verification respectively, it was proved that the improved SMO control strategy can significantly reduce chattering and phase delay, and can maintain good estimation performance at low speeds.

\section{Analysis of the SPMSM Sensorless Control System}

Figure 1 shows a sensorless control block diagram of a surface-mounted permanent magnet synchronous motor based on an improved sliding film observer. The whole system includes SPMSM (surface permanent magnet synchronous motor), a three-phase inverter module, a SVPWM module, a vector control module, and an improved SMO module. The vector controlling method sets $i_{d}=0$ and applies Clark transformation to convert the threephase current and voltage collected by the sensor into the current component $i_{\alpha}$ and voltage component $u_{\alpha}$ on the $\alpha$ axis, the current component $i_{\beta}$ and voltage component $u_{\beta}$ on the $\beta$ axis, in a two-phase stationary coordinate system. Then the $i_{\alpha}, i_{\beta}, u_{\alpha}, u_{\beta}$ components are the input to the improved SMO module. The motor speed and position information estimated by the improved sliding mode observer module are calibrated through the speed loop PI controller and the current loop controller. The calibrated output is the voltage component $u_{d} *$ on the $\mathrm{d}$ axis and the voltage component $u_{q} *$ on the $\mathrm{q}$ axis in the synchronous rotating coordinate system. Then, the voltage components in the two-phase stationary coordinate system are modulated through the inverter after space vector pulse width modulation SVPWM, and the voltage is converted to three-phase alternating current which is supplied to the motor. Finally, the motor control system forms a closed control loop. 


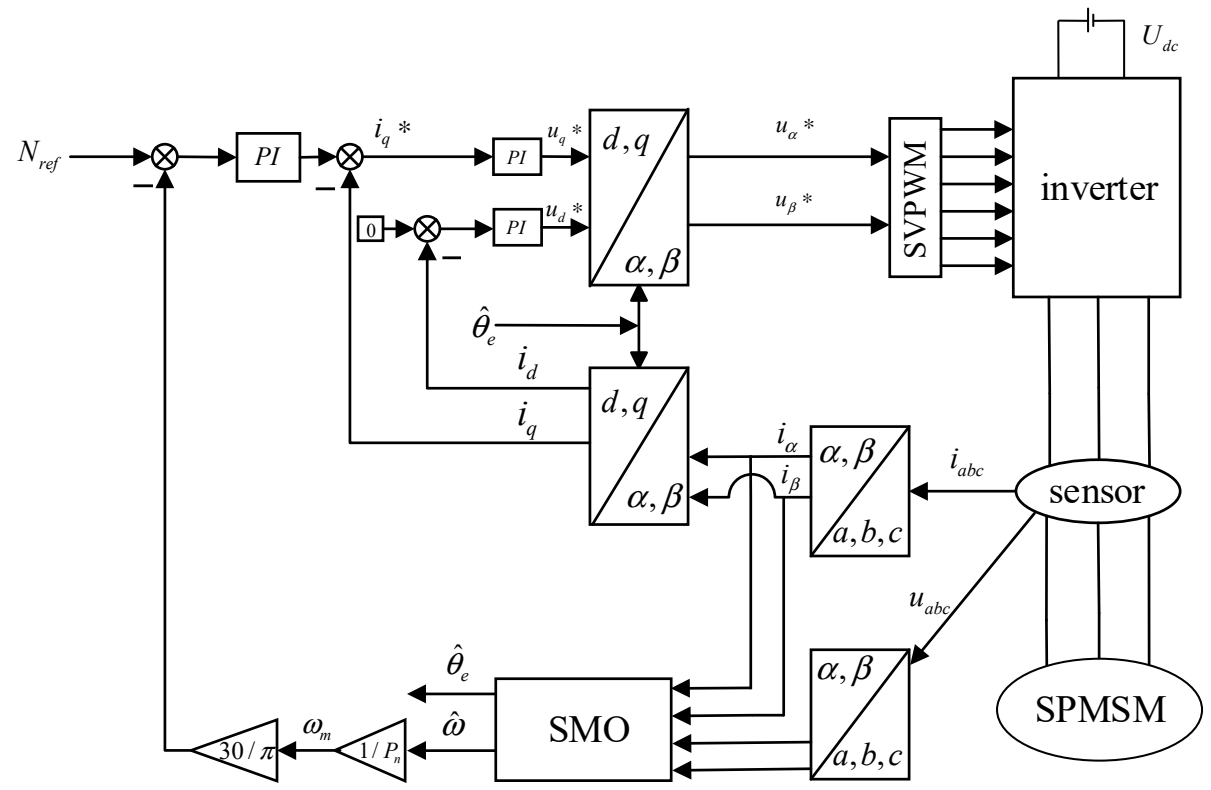

Figure 1. Block diagram of sensor-less control of the surface mounted permanent magnet synchronous motor based on improved SMO.

The surface mounted permanent magnet synchronous motor (SPMSM) has the advantages of simple structure, strong anti-interference capability, and manageable control performance and is widely used in systems that require high precision [21]. Therefore, this article concerns the study of SPMSM. The equation of states of the stationary coordinate system ( $\alpha \beta$ coordinate system) SPMSM is given below:

$$
\left\{\begin{array}{l}
\frac{d i_{\alpha}}{d t}=-\frac{R_{S}}{L_{S}} i_{\alpha}-\frac{e_{\alpha}}{L_{S}}+\frac{u_{\alpha}}{L_{S}} \\
\frac{d i_{\beta}}{d t}=-\frac{R_{S}}{L_{S}} i_{\beta}-\frac{e_{\beta}}{L_{S}}+\frac{u_{\beta}}{L_{S}}
\end{array}\right.
$$

where $e_{\alpha}$ and $e_{\beta}$ are given by

$$
\left\{\begin{array}{l}
e_{\alpha} \\
e_{\beta}
\end{array}=\left[\begin{array}{l}
-\Psi \omega \sin \theta \\
\Psi \omega \cos \theta
\end{array}\right]\right.
$$

where $u_{\alpha}$ and $u_{\beta}$ are two-phase stator voltages respectively; $i_{\alpha}$ and $i_{\beta}$ are two-phase stator currents respectively; $e_{\alpha}$ and $e_{\beta}$ are two opposite electromotive forces respectively; $R_{S}$ is the stator resistance; $\theta$ is the rotor position angle; $L_{S}$ is the stator inductance; $\omega$ is the rotor angular velocity; $\Psi$ is the rotor flux.

Given Equation (2), the position and speed of the SPMSM rotor can be derived as:

$$
\left\{\begin{array}{l}
\theta=-\arctan \frac{e_{\alpha}}{e_{\beta}} \\
\omega=\frac{\sqrt{e_{\alpha}^{2}+e_{\beta}^{2}}}{\Psi}
\end{array}\right.
$$

\section{Analysis of Traditional SMO}

\subsection{Traditional SMO Observer Design}

Given Equation (3), to obtain the rotor position and speed of SPMSM, the back-EMF signal can be accurately estimated. The equation for traditional SMO control is given by

$$
\left\{\begin{array}{l}
\frac{d \hat{i}_{\alpha}}{d t}=-\frac{R_{S}}{L_{S}} \hat{i}_{\alpha}+\frac{u_{\alpha}}{L_{S}}-\frac{K}{L_{S}} \operatorname{sign}\left(\hat{i}_{\alpha}-i_{\alpha}\right) \\
\frac{d \hat{i}_{\beta}}{d t}=-\frac{R_{S}}{L_{S}} \hat{i}_{\beta}+\frac{u_{\beta}}{L_{S}}-\frac{K}{L_{S}} \operatorname{sign}\left(\hat{i}_{\beta}-i_{\beta}\right)
\end{array}\right.
$$


where $\hat{i}_{\alpha}$ and $\hat{i}_{\beta}$ are the estimated values of the two-phase stator currents respectively; $\operatorname{sign}(x)$ is the switch function; $K$ is the gain factor.

By subtracting Formula (1) from Formula (4), we can obtain the current error equation of SPMSM:

$$
\left\{\begin{array}{l}
\frac{d\left(\hat{i}_{\alpha}-i_{\alpha}\right)}{d t}=-\frac{R_{S}}{L_{S}}\left(\hat{i}_{\alpha}-i_{\alpha}\right)+\frac{e_{\alpha}}{L_{S}}-\frac{K}{L_{S}} \operatorname{sign}\left(\hat{i}_{\alpha}-i_{\alpha}\right) \\
\frac{d\left(\hat{i}_{\beta}-i_{\beta}\right)}{d t}=-\frac{R_{S}}{L_{S}}\left(\hat{i}_{\beta}-i_{\beta}\right)+\frac{e_{\beta}}{L_{S}}-\frac{K}{L_{S}} \operatorname{sign}\left(\hat{i}_{\beta}-i_{\beta}\right)
\end{array}\right.
$$

Since the input control quantity is a discontinuous discrete signal, it is usually necessary to extract a continuous back-EMF signal from the motor via an external low-pass filter. Then the estimation equations of back EMF $\hat{e}_{\alpha}$ and $\hat{e}_{\beta}$ are given by

$$
\left\{\begin{array}{l}
\hat{e}_{\alpha}=\frac{\omega_{c}}{\omega_{c}+S} Z_{\alpha} \\
\hat{e}_{\beta}=\frac{\omega_{c}}{\omega_{c}+S} Z_{\beta}
\end{array}\right.
$$

where $\omega_{c}$ is the cutoff frequency of the low pass filter;

$$
\left\{\begin{array}{l}
Z_{\alpha}=-\frac{R_{S}}{L_{S}}\left(\hat{i}_{\alpha}-i_{\alpha}\right)+\frac{e_{\alpha}}{L_{S}}-\frac{K}{L_{S}} \operatorname{sign}\left(\hat{i}_{\alpha}-i_{\alpha}\right) \\
Z_{\beta}=-\frac{R_{S}}{L_{S}}\left(\hat{i}_{\beta}-i_{\beta}\right)+\frac{e_{\beta}}{L_{S}}-\frac{K}{L_{S}} \operatorname{sign}\left(\hat{i}_{\beta}-i_{\beta}\right)
\end{array}\right.
$$

According to Formula (3), the estimated value of the SPMSM rotor position and speed can be obtained:

$$
\left\{\begin{array}{l}
\hat{\theta}_{e q}=-\arctan \frac{\hat{e}_{\alpha}}{\hat{e}_{\beta}} \\
\hat{\omega}=\frac{\sqrt{\hat{e}_{\alpha}{ }^{2}+\hat{e}_{\beta}{ }^{2}}}{\Psi}
\end{array}\right.
$$

The extraction of the back-EMF signal via a low-pass filter brings a phase delay phenomenon and errors between the estimated rotor position and the actual position, and the magnitude of the error is inversely proportional to the cutoff frequency. Usually a certain angle compensation is added after the rotor position estimate to reduce the error between the estimated value and the actual value. Thus, the final estimate of corner $\hat{\theta}_{e}$ is:

$$
\hat{\theta}_{e}=-\arctan \frac{\hat{e}_{\alpha}}{\hat{e}_{\beta}}+\arctan \frac{\hat{\omega}}{\omega_{c}}
$$

\subsection{Traditional SMO Control Simulation Analysis}

This paper builds a simulation model of traditional the SMO algorithm in Matlab/Simulink. The simulation model takes a surface-mounted permanent magnet synchronous motor as an example, and the specific parameters of the motor are shown in Table 1 . The system simulation time is set to $0.1 \mathrm{~s}$, and the system speed is changed abruptly at $0.05 \mathrm{~s}$ for further verification of the stability and tracking performance of the system.

Table 1. SPMSM parameters.

\begin{tabular}{ccc}
\hline Parameter & Unit & Value \\
\hline Stator resistance & $R / \Omega$ & 2.875 \\
Flux linkage & $\Psi / W b$ & 0.175 \\
Moment of inertia & $\mathrm{J} / \mathrm{kg} \cdot \mathrm{m}^{2}$ & 0.001 \\
Number of pole pairs & $P_{n}$ & 4 \\
Stator inductance & $\mathrm{L}_{\mathrm{s}} / \mathrm{mH}$ & 8.5 \\
\hline
\end{tabular}

The actual value of the motor speed and rotor position is represented by a black curve, and the estimated value is represented by a red curve. Figures 2 and 3 are the curve comparisons of the actual and estimated values of the motor speed and rotor position of the traditional SMO respectively. First, the motor speed is set at $50 \mathrm{rad} / \mathrm{s}$, and the speed suddenly changes to $100 \mathrm{rad} / \mathrm{s}$ at $0.05 \mathrm{~s}$. 


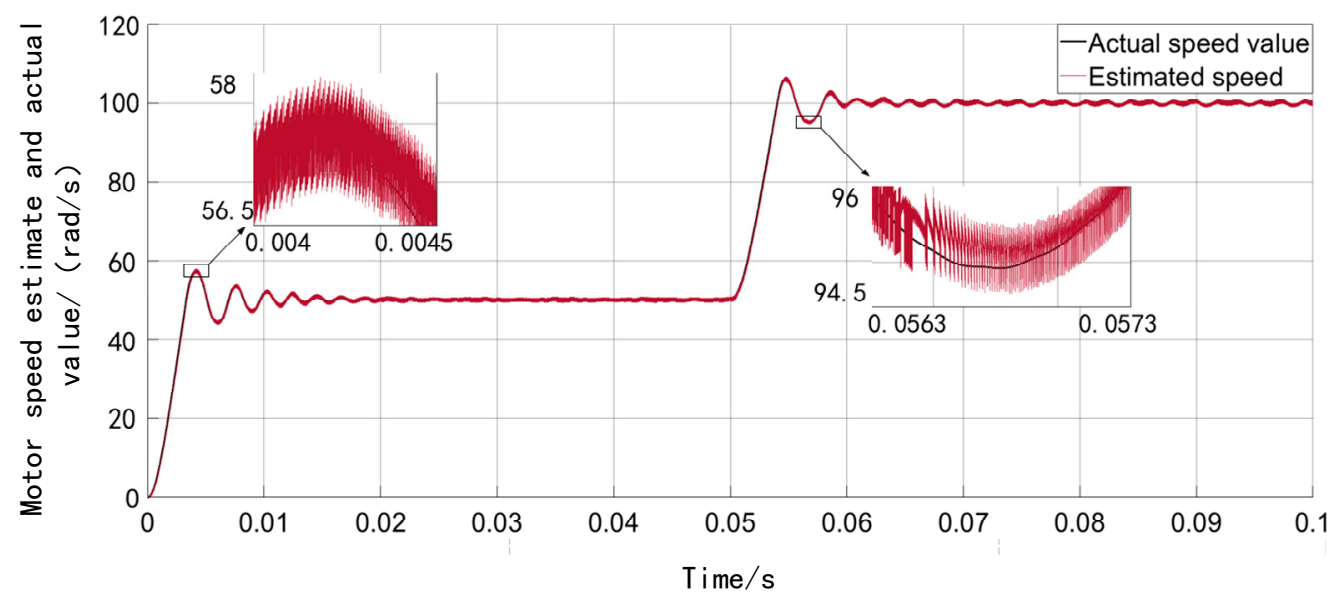

Figure 2. SMO Comparison of the motor speed of the traditional SMO observer at high speed.

In Figure 2, when the red curve tracks the black curve, there are obvious burr and chatter in the red curve. This shows that traditional SMO has a large high frequency chattering phenomenon in the high-speed operation of the system due to the traditional SMO applying the sign function as the control function of the system. Because of the sudden change of the sign function at the zero point, the system appears as high-frequency chattering.

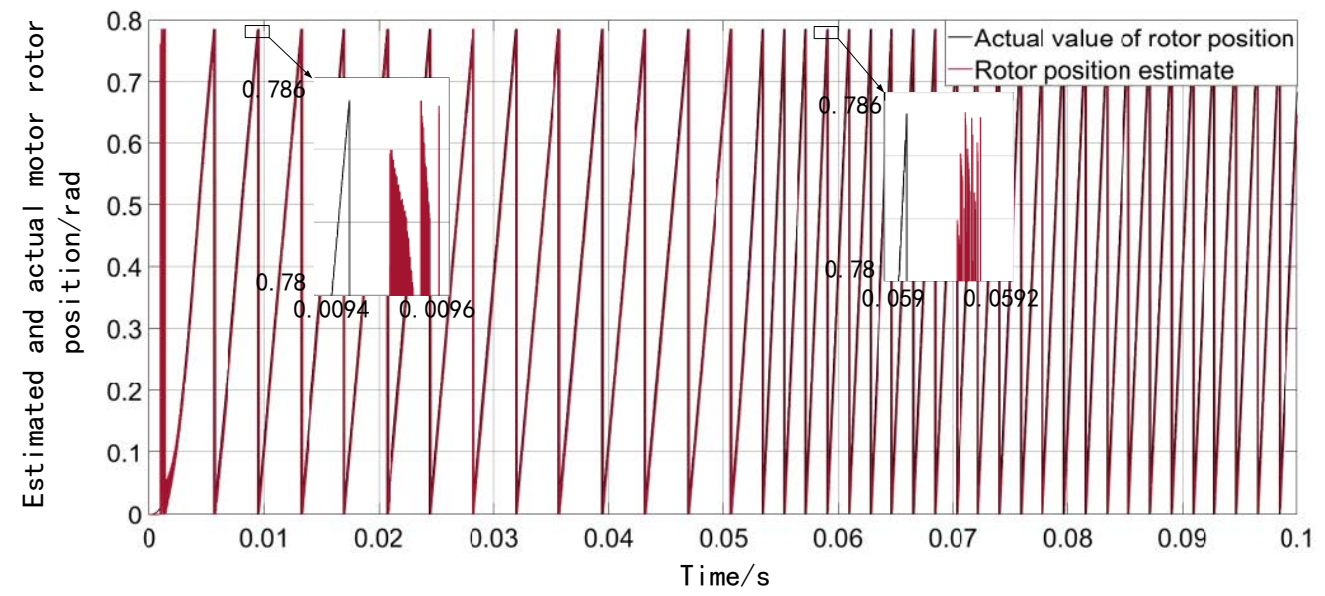

Figure 3. SMO Comparison diagram of the motor rotor position of the traditional SMO observer at high speed.

It can be seen from Figure 3 that when the red curve tracks the black curve, there is a large time delay between the red and black curves which shows that the traditional SMO has a large phase delay in the high-speed operation of the system because the traditional SMO usually applies an external low-pass filter to extract the discrete back-EMF signal and brings a phase delay in the system.

Figure 4 is a comparison chart of the speed of the traditional SMO running under the system low speed condition. The given motor speed is $2 \mathrm{rad} / \mathrm{s}$. 


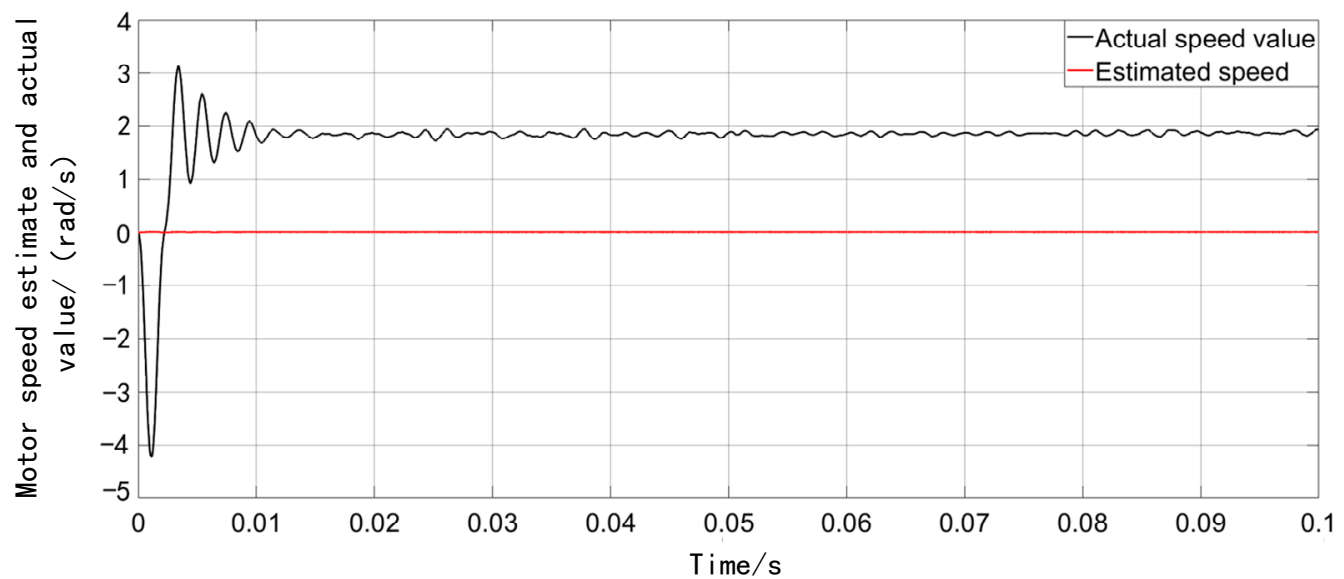

Figure 4. Comparison chart of the motor speed of the traditional SMO observer at low speed.

When the permanent magnet synchronous motor is running at low speed, due to the weak back-EMF signal and high-frequency chattering and other interference signals, it is difficult for the traditional SMO slip film observer to accurately determine the speed and rotor position of the permanent magnet synchronous motor at low speeds. In Figure 4, the red and black curves do not overlap at all, indicating that the traditional SMO observer fails under low-speed system operation.

\section{New and Improved SMO Control Strategy}

\subsection{Improvement of Switching Function}

The switching function of the traditional sliding film control strategy is a sign function. The discontinuity of the sign function at the zero-point results in high-frequency chatter in the system. To address this issue, many scholars have aimed to improve it, including the saturation function sat(s), continuous function theta(s), arctangent function atan(s), hyperbolic tangent function tanh(s), sigmoid(s) function to replace the sign function signum(s) in the traditional synovial control strategy. The graphs of various switching functions are shown below.

It can be seen from Figure 5 that the value of the blue curve (sign function) changes from -1 to 1 at the zero-crossing point. The sudden change of this function makes the whole system appear as high-frequency chattering. To improve this problem, a function that is excessively smoother at the zero point should be selected, while the convergence rate characteristics of the function should also be considered. Based on the above considerations and the results in Figure 5, this paper utilizes a continuous, smooth and dynamically variable sigmoid(s) to replace the symbolic function in the traditional synovial control strategy.

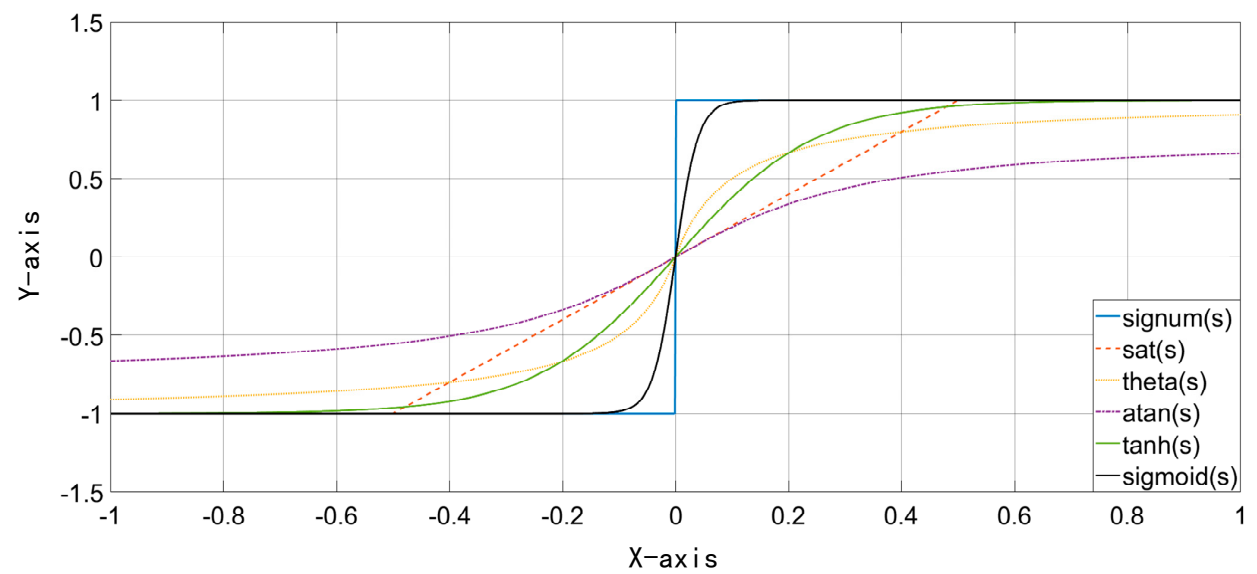

Figure 5. Comparison of curves of different functions. 
The sigmoid(s) expression is as follows:

$$
\operatorname{sigmoid}(s)=\frac{2}{1+\exp (-a s)}-1
$$

where $a$ is a key factor.

The value of $a$ will directly affect the convergence speed of the function. Thus, selecting an appropriate value for $a$ can improve the robustness of the system and better reduce the system chattering and phase delay.

The equation for designing improved $\mathrm{SMO}$ control is given by

$$
\left\{\begin{array}{l}
\frac{d \hat{i}_{\alpha}}{d t}=-\frac{R_{S}}{L_{S}} \hat{i}_{\alpha}+\frac{u_{\alpha}}{L_{S}}-\frac{K_{S}}{L_{S}} \operatorname{sigmoid}\left(\hat{i}_{\alpha}-i_{\alpha}\right) \\
\frac{d \hat{i}_{\beta}}{d t}=-\frac{R_{S}}{L_{S}} \hat{i}_{\beta}+\frac{u_{\beta}}{L_{S}}-\frac{K_{S}}{L_{S}} \operatorname{sigmoid}\left(\hat{i}_{\beta}-i_{\beta}\right)
\end{array}\right.
$$

where $K_{S}$ is the optimized function gain [22].

According to Equations (1)-(11), the current error equation of SPMSM of improved $\mathrm{SMO}$ control can be given by

$$
\left\{\begin{array}{l}
\frac{d\left(\hat{i}_{\alpha}-i_{\alpha}\right)}{d t}=-\frac{R_{S}}{L_{S}}\left(\hat{i}_{\alpha}-i_{\alpha}\right)+\frac{e_{\alpha}}{L_{S}}-\frac{K_{S}}{L_{S}} \operatorname{sigmoid}\left(\hat{i}_{\alpha}-i_{\alpha}\right) \\
\frac{d\left(\hat{i}_{\beta}-i_{\beta}\right)}{d t}=-\frac{R_{S}}{L_{S}}\left(\hat{i}_{\beta}-i_{\beta}\right)+\frac{e_{\beta}}{L_{S}}-\frac{K_{S}}{L_{S}} \operatorname{sigmoid}\left(\hat{i}_{\beta}-i_{\beta}\right)
\end{array}\right.
$$

The sliding surface is selected as $S_{h}=\left[\hat{i}_{\alpha}-i_{\alpha} \hat{i}_{\beta}-i_{\beta}\right]^{T}$. According to the sliding film structure control strategy, we define $S_{h}=0$ as the sliding surface of the system. When the system continuously operates with high frequency and small amplitude on the sliding mode surface, and finally approximately coincides with the sliding mode surface, the value of the estimated current can be regarded as the actual value. The key control factor is the back-EMF signal generated when the system is running.

The Lyapunov criterion is used in the literature [22], and the stability analysis of the improved SMO control strategy based on the sigmoid function is introduced in detail and will not be mentioned here again.

\subsection{Filter Improvements}

To obtain the back-EMF signal, traditional methods often use a low-pass filter with a fixed cut-off frequency to extract the estimated value of the back-EMF, and then perform arctangent calculation on the estimated back-EMF to obtain the estimated value of the SPMSM rotor position and speed (Formulas (6)-(9)). However, the accuracy is poor because it cannot perform the appropriate filter adjustments based on changes in the input signal in real time. The extracted signal contains a lot of interference signals, and it is impossible to accurately extract the required back-EMF signal, which leads to problems of high-frequency chattering, phase delay, and observation failure in the low-speed section of traditional SMO. In order to solve the above problems, this paper uses the recursive least-squares (Recursive Least-Squares, RLS) algorithm adaptive filter to replace the low-pass filter in the traditional sliding mode control strategy.

The RLS adaptive filter used in this article requires discrete input signals, so the continuous signal of the improved SMO algorithm should be discretely processed before inputting the RLS adaptive filter.

The RLS adaptive filter calculates and updates the weights and coefficients of the FIR (Finite Impulse Response, FIR) filter in real time through the recursive least squares algorithm, and filters the signal of the input filter through an adaptive weight control strategy to get the optimal Waveform. The matrix equation of the RLS adaptive filter is expressed as follows:

$$
K(n)=\frac{\lambda^{-1} P(n-1) u(n)}{1+\lambda^{H} P(n-1) u(n)}
$$




$$
\begin{gathered}
y(n)=\omega(n-1) u(n) \\
e(n)=d(n)-y(n) \\
\omega(n)=\omega(n-1)+k^{H}(n) e(n) \\
P(n)=\lambda^{-1} P(n-1)-\lambda^{-1} k(n) u^{H} P(n-1)
\end{gathered}
$$

where $n$ is the current time index; $u(n)$ is the step $\mathrm{n}$ buffer of the vector of input samples; $P(n)$ is the inverse covariance matrix of the nth step; $k(n)$ is the gain vector at step $\mathrm{n} ; \omega(n)$ is the vector estimated by the filter tap of the $\mathrm{n}$-th step; $y(n)$ is the filtered output at step $\mathrm{n}$; $e(n)$ is the n-step estimation error; $d(n)$ is the expected response at step $\mathrm{n} ; \lambda$ is the forgetting factor; $u(n)$ and $d(n)$ correspond to the current error input samples in the SMO; $y(n)$ is the estimated back-EMF output from the RLS adaptive filter, and $\lambda$ is 1 .

The algorithm block diagram is shown in Figure 6, and the signal flow diagram of the RLS adaptive filter is shown in Figure 7.

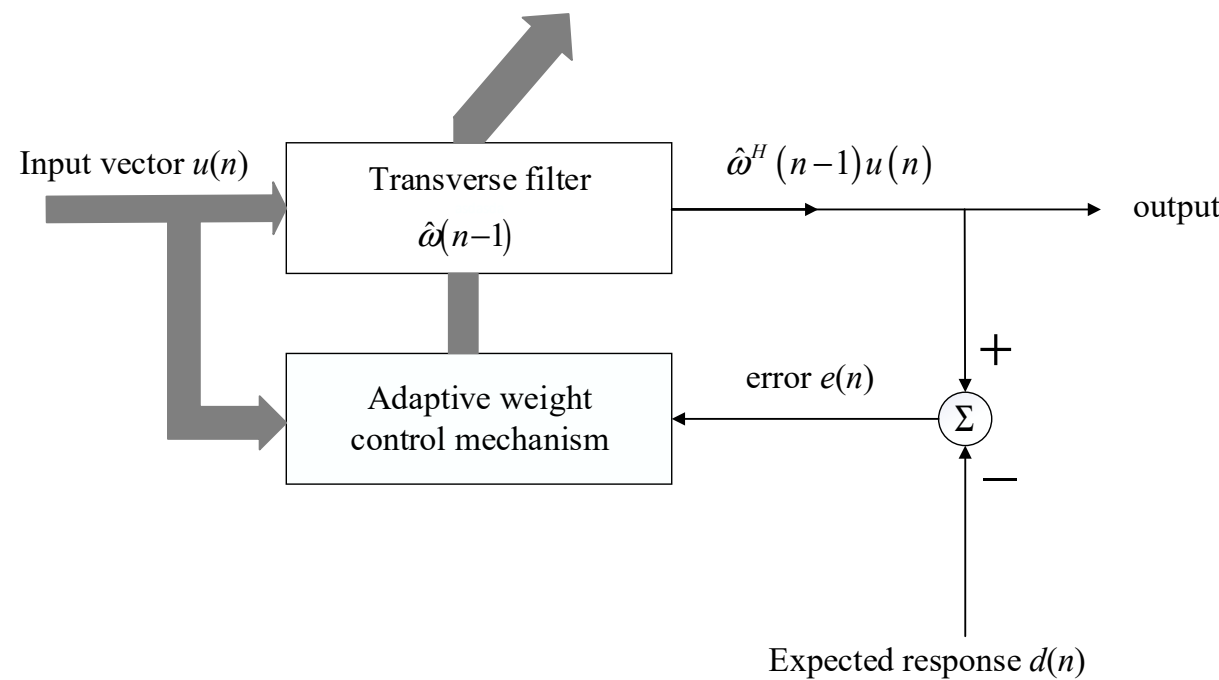

Figure 6. RLS algorithm block diagram.

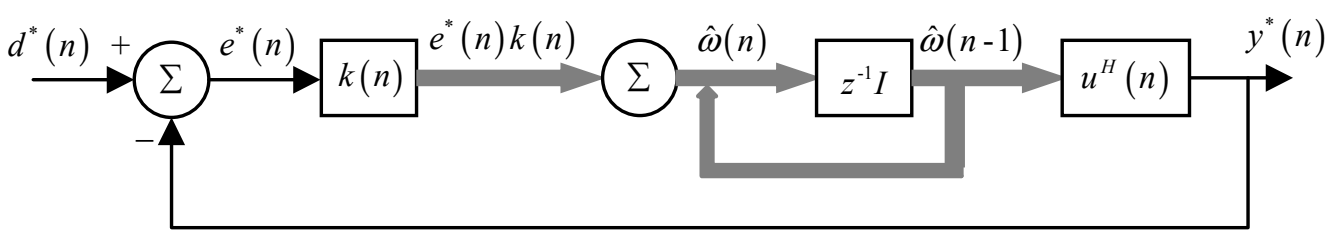

Unit negative feedback

Figure 7. RLS signal flow diagram.

Although the RLS adaptive filter has greatly improved all aspects compared with the traditional low-pass filter, it will inevitably bring some phase delay problems. In order to reduce the influence of the phase delay, an angle compensation is added to the estimated value of the rotor position to reduce the error between the estimated value and the actual value. The final estimate of corner $\hat{\theta}_{e}$ is:

$$
\hat{\theta}_{e}=-\arctan \frac{\hat{e}_{\alpha}}{\hat{e}_{\beta}}+\arctan K \hat{\omega}
$$

where $K$ is the commonly used coefficient for phase angle compensation of the filter.

The improved SMO control strategy based on the sigmoid function and the RLS adaptive filter reduces the chattering phenomenon of the switching function in the transition phase compared to the traditional SMO control strategy. Meanwhile, the adaptive filtering 
method improves the extraction accuracy of the back-EMF signal. The problems such as high-frequency chattering, phase delay, and difficulty in extracting fundamental signals at low speeds have been significantly alleviated. The block diagram of the improved SMO algorithm is shown in Figure 8.

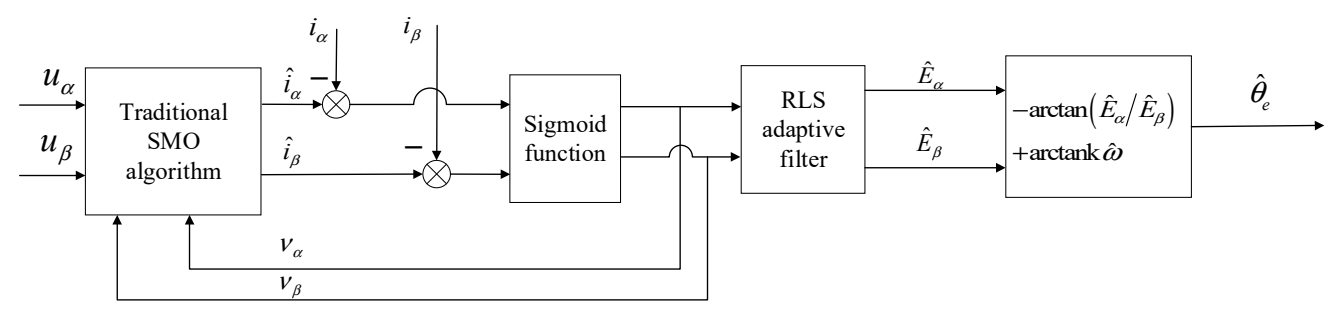

Figure 8. Principle block diagram of the new improved SMO algorithm.

\section{System Simulation Result Analysis}

Aiming at the problems of the above-mentioned SMO algorithm, this paper proposes an improved SMO algorithm. The sigmoid function is substituted for the hyperbolic tangent function in the improved SMO algorithm to further reduce the high-frequency chattering phenomenon and increase the convergence rate of the system. Focusing on the problems of phase delay and difficulty in extracting back-EMF signals at low speeds. The low-pass filter with a fixed cutoff frequency used in the improved SMO algorithm and the RLS adaptive filter with variable cut-off frequency replace the traditional low-pass filter.

A simulation model was built in Matlab/Simulink for testing. An improved SMO based on sigmoid(s) function and RLS adaptive filter was established. The simulation model applies a surface-mounted permanent magnet synchronous motor. The specific parameters of the motor are as in Table 1. The red in the figure below is the estimated curve, and the black is the actual curve. The system simulation time is set to $0.1 \mathrm{~s}$, and the speed is changed abruptly at a certain time in the middle of the system to further verify the stability and tracking performance of the system.

Figures 9 and 10 show the curve comparison diagrams of the actual and estimated values of the motor speed and rotor position of the new and improved SMO, respectively. First, the motor speed is set to $50 \mathrm{rad} / \mathrm{s}$, and the speed suddenly changes to $100 \mathrm{rad} / \mathrm{s}$ at $0.05 \mathrm{~s}$.

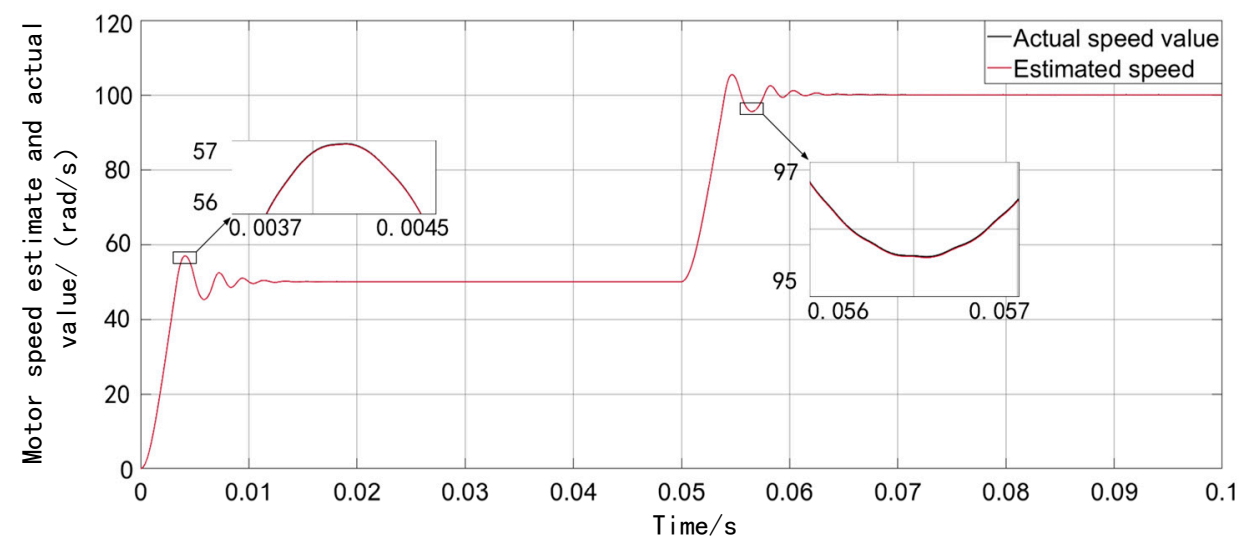

Figure 9. Comparison chart of motor speed of the new and improved SMO at high speed.

Comparing Figure 9 with Figures 2, 3 and 10 respectively, the new improved SMO greatly reduces high-frequency chattering and phase delay when the system is running at high speed compared to the traditional SMO, and the system has a faster convergence rate and faster, better tracking performance. 


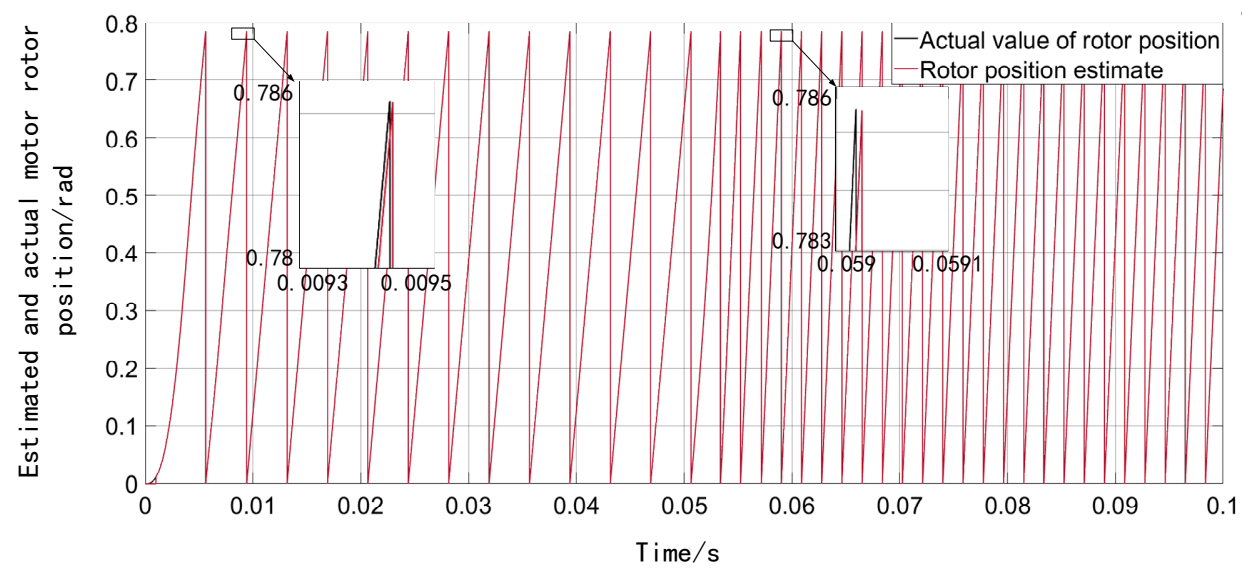

Figure 10. Comparison chart of the motor rotor position of the new and improved SMO at high speed.

Figures 11 and 12 show the curve comparison diagrams of the motor speed and rotor position of the new and improved SMO running at low system speeds. First, the motor speed is set to $1 \mathrm{rad} / \mathrm{s}$ and then the speed changes to $10 \mathrm{rad} / \mathrm{s}$ at $0.05 \mathrm{~s}$.

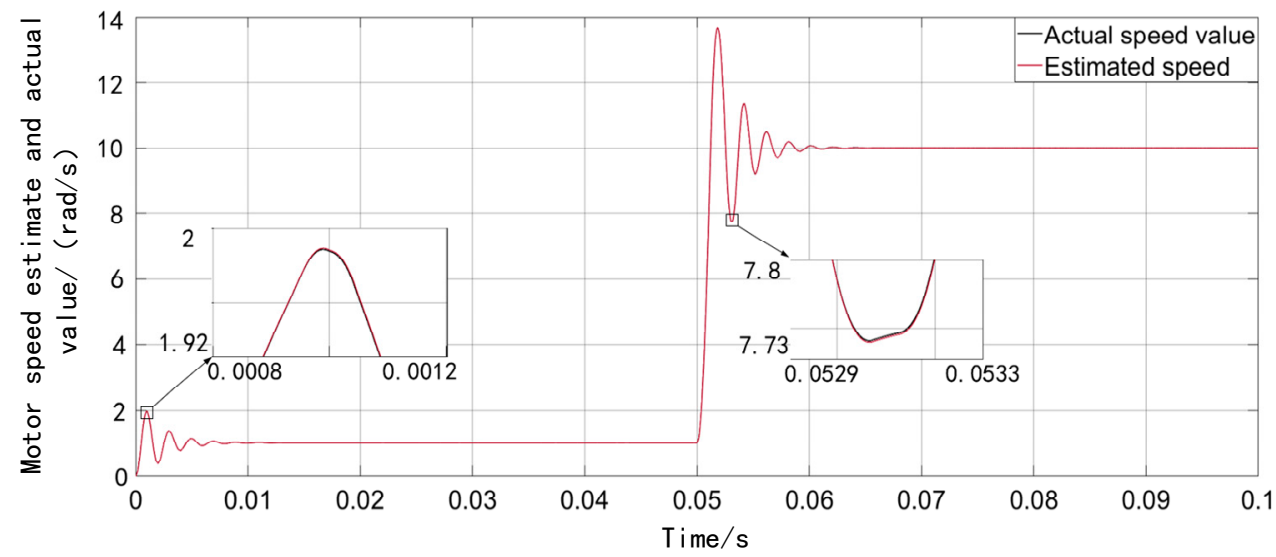

Figure 11. Comparison chart of motor speed of the new and improved SMO at low speed.

Comparing Figures 4 and 11, the improved SMO based on the sigmoid function and RLS adaptive filter not only solves the problem of traditional SMO failure in the low-speed section, but also the high-frequency chattering that occurs during system operation.

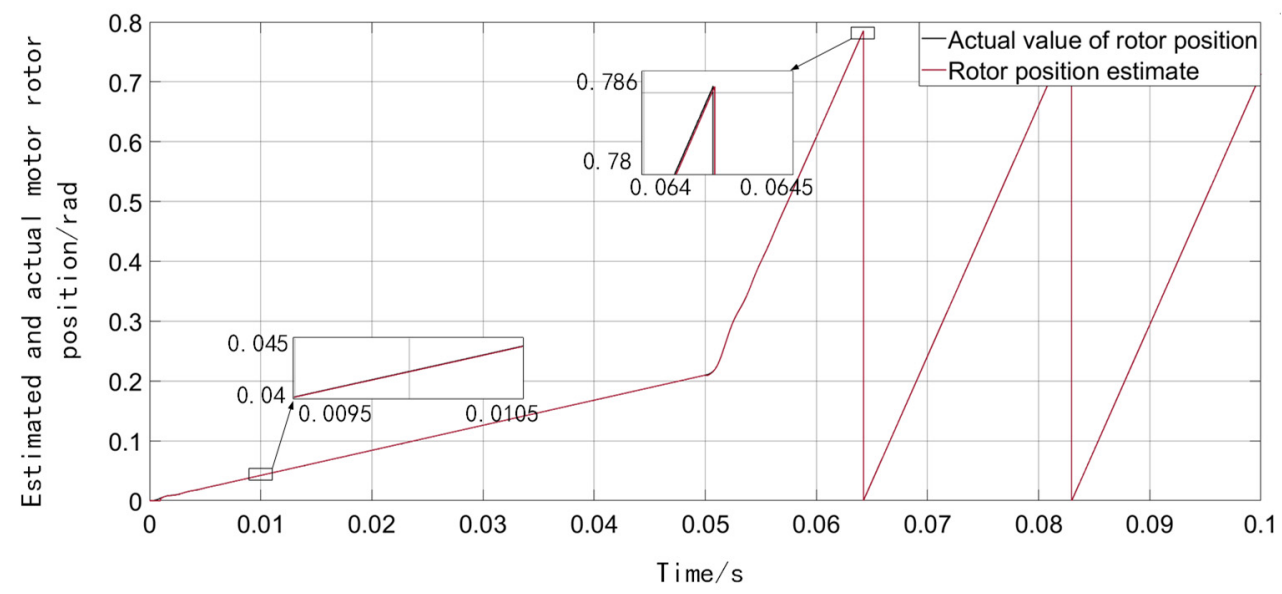

Figure 12. Comparison chart of the motor rotor position of the new and improved SMO at low speed. 
In Figure 11, the newly improved SMO can accurately estimate the position of the motor rotor when the system is running at low speed.

From Figures 11 and 12, the newly improved SMO based on the sigmoid function and the RLS adaptive filter solves the problem of the fundamental wave model control strategy when taking the sliding mode control strategy. It is difficult to control the motor speed, rotor position, and other information at low speeds. There is a problem of making estimates.

To more intuitively demonstrate the improved performance of the improved SMO for motor speed and rotor position estimation accuracy compared with the traditional SMO, the simulation test was specially selected in the low-speed section where the back EMF is small.

Figures 13 and 14 show the variation curves of the estimation error of the motor speed for the traditional SMO and the new improved SMO under the system of low-speed operating conditions. The motor speed is set to $10 \mathrm{rad} / \mathrm{s}$.

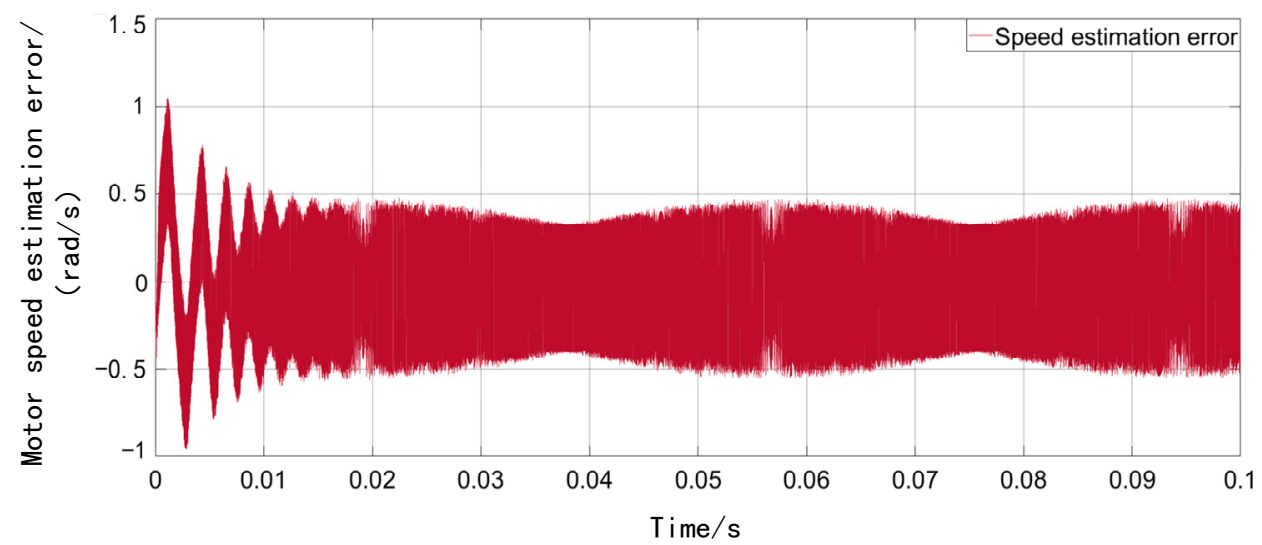

Figure 13. The variation curve of the speed estimation error of the traditional SMO at low speed.

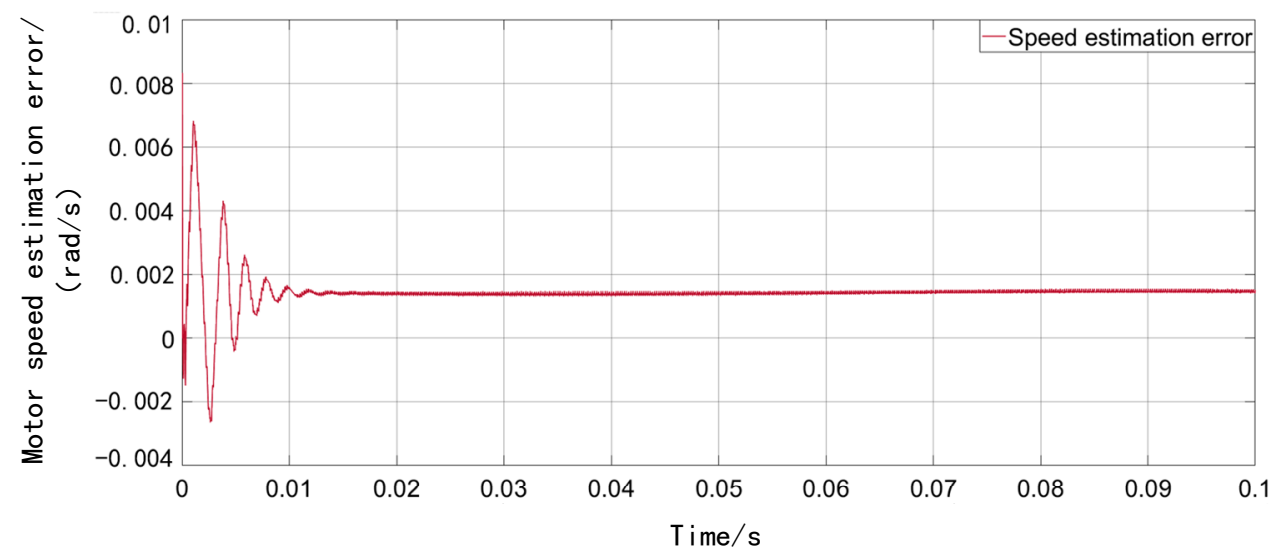

Figure 14. The variation curve of the new and improved SMO speed estimation error at low speed.

Comparing Figure 13 with Figure 14, the speed estimation error of the traditional $\mathrm{SMO}$ is about $\pm 0.5 \mathrm{rad} / \mathrm{s}$, and the speed estimation error of the new improved SMO is about $0.0015 \mathrm{rad} / \mathrm{s}$. This proves that the new improved SMO is optimized for the accuracy of motor speed estimation.

Figures 15 and 16 show the variation curves of the estimation error of the rotor position of the motor under the low-speed operating conditions of the traditional SMO and the new improved SMO, respectively. The motor speed is set to $10 \mathrm{rad} / \mathrm{s}$. 


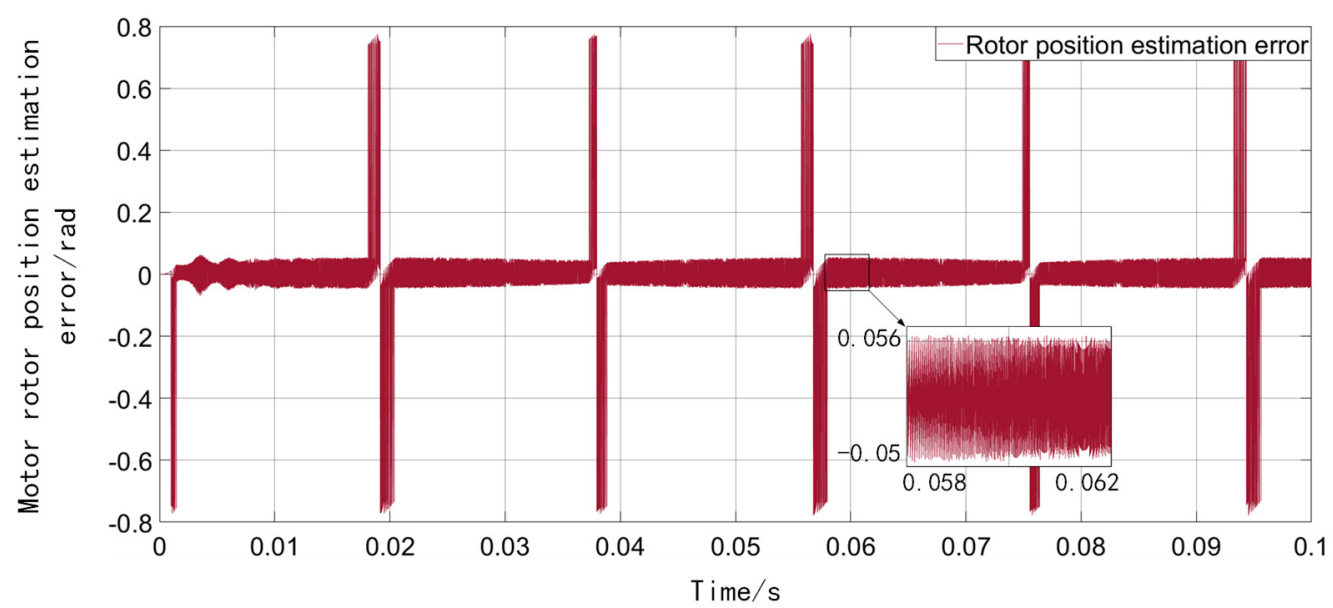

Figure 15. The variation curve of the rotor position estimation error of the traditional SMO at low speed.

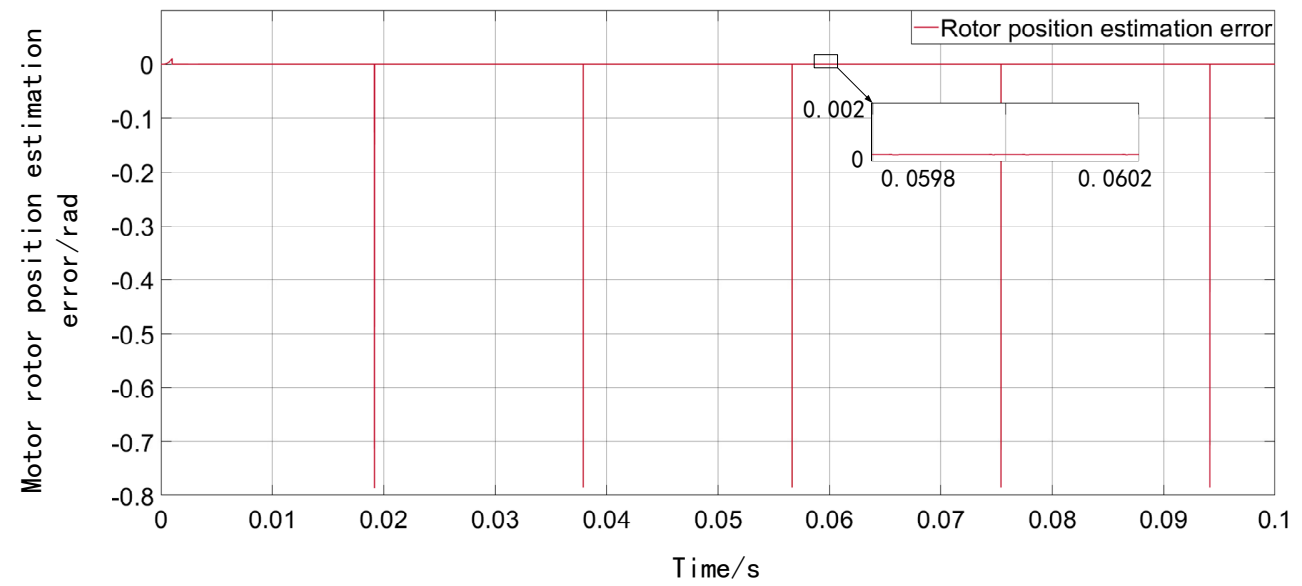

Figure 16. Variation curve of the rotor position estimation error of the new improved SMO at low speed.

Comparing Figure 15 with Figure 16, it can be seen intuitively that the rotor position estimation error of the traditional SMO is about $\pm 0.05 \mathrm{rad}$, and the rotor position estimation error of the new improved SMO is about $0.0005 \mathrm{rad}$. This proves that the new improved $\mathrm{SMO}$ is optimized for the estimation accuracy of the motor rotor position.

Figures 17 and 18 show the variation curves of the estimated values of the opposite electromotive force of the motor under the low-speed operating conditions of the traditional SMO and the new improved SMO (the red curve is $\hat{e}_{\alpha}$ and the black curve is $\hat{e}_{\beta}$ ). The motor speed is set to $10 \mathrm{rad} / \mathrm{s}$. 


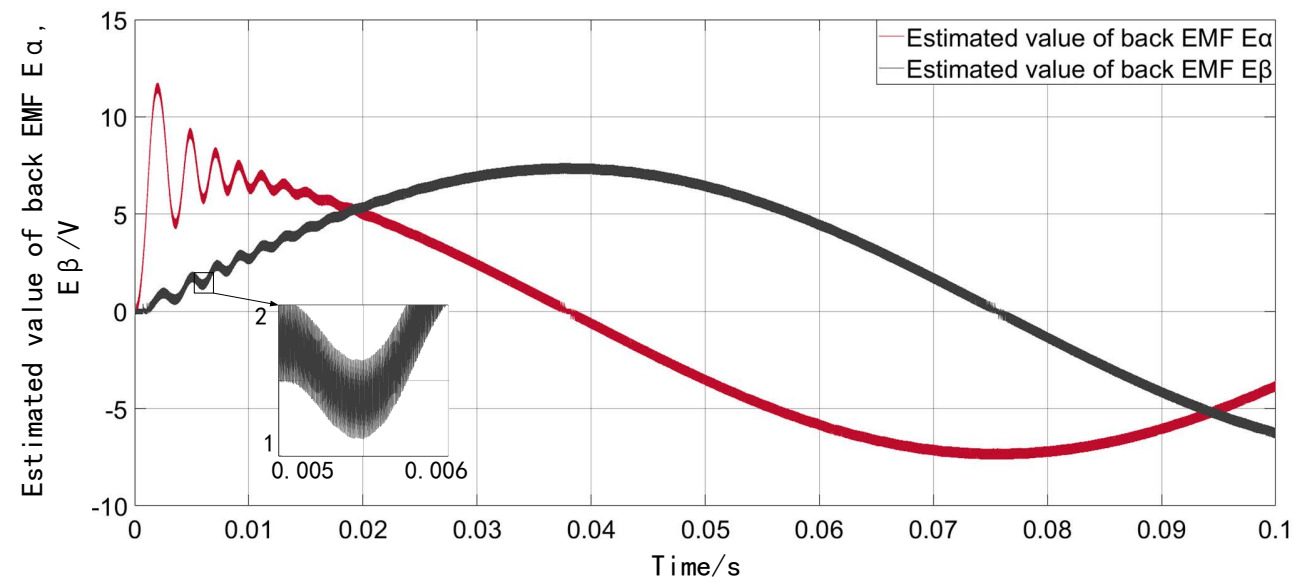

Figure 17. The variation curve of the estimated value of two opposite electromotive forces at low speed of the traditional SMO.

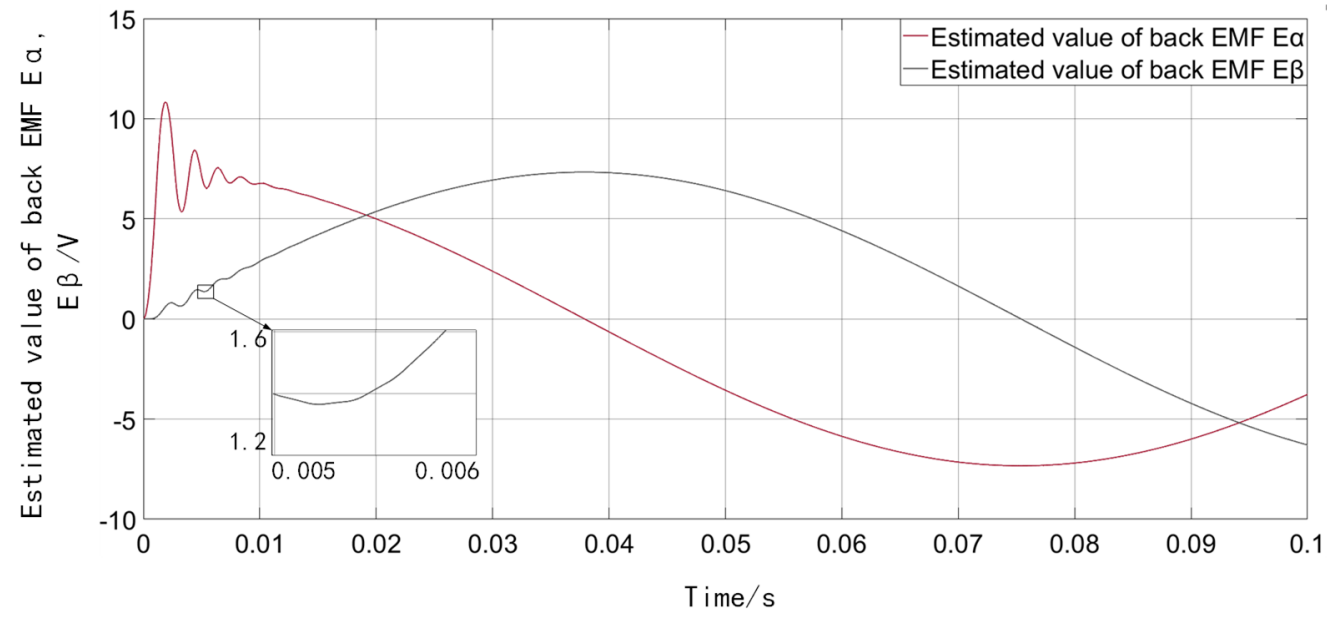

Figure 18. The curve of the estimated value of the two opposite electromotive forces of the new and improved SMO at low speed.

Comparing Figures 17 and 18, intuitively, the RLS adaptive filter used in the new improved SMO has greatly improved the filtering performance compared to the low-pass filter used in the traditional SMO. The precise back-EMF signal lays the foundation for the new and improved SMO to achieve a better observation effect on the motor speed and rotor position information in the full speed section.

To observe the phenomenon that the motor continuously changes the speed during the driving process of an electric vehicle, Figures 19 and 20 compare the actual and estimated values of the motor speed and rotor position of the new and improved SMO when the system is running at full speed (the red curve is the estimated value, and the black curve is the actual value). First, the given motor speed is $1 \mathrm{rad} / \mathrm{s}$, then the speed changes to $30 \mathrm{rad} / \mathrm{s}$ at $0.02 \mathrm{~s}$, the speed changes to $140 \mathrm{rad} / \mathrm{s}$ at $0.04 \mathrm{~s}$, and the speed changes to $60 \mathrm{rad} / \mathrm{s}$ at $0.07 \mathrm{~s}$. 


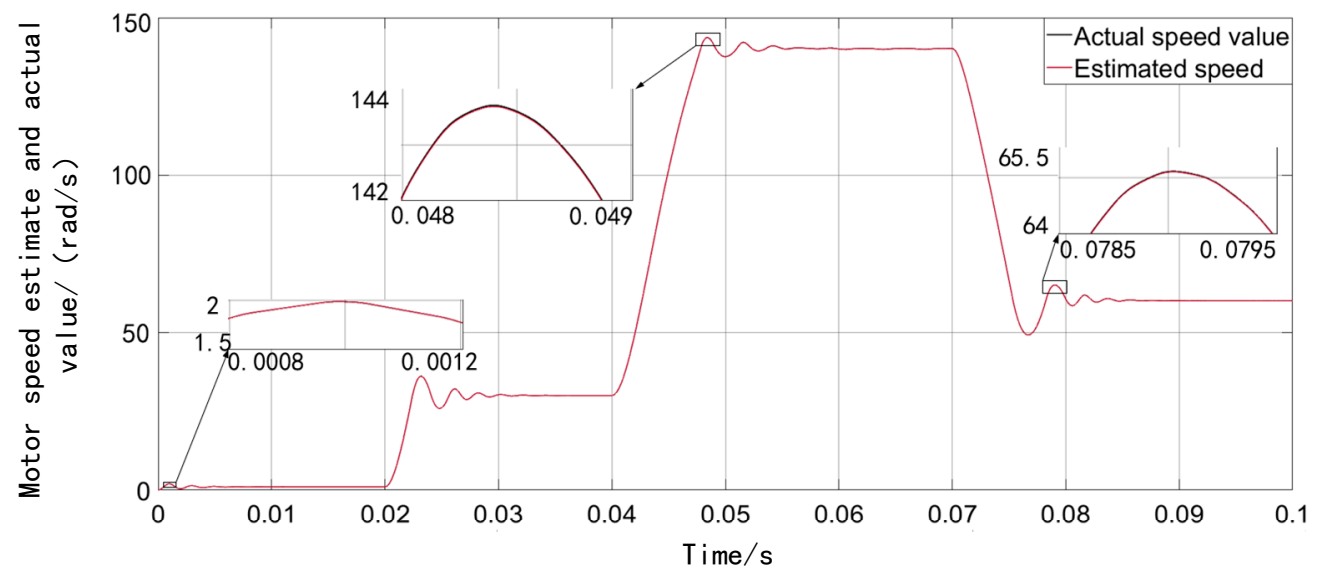

Figure 19. The motor speed comparison chart of the new and improved SMO at full speed.

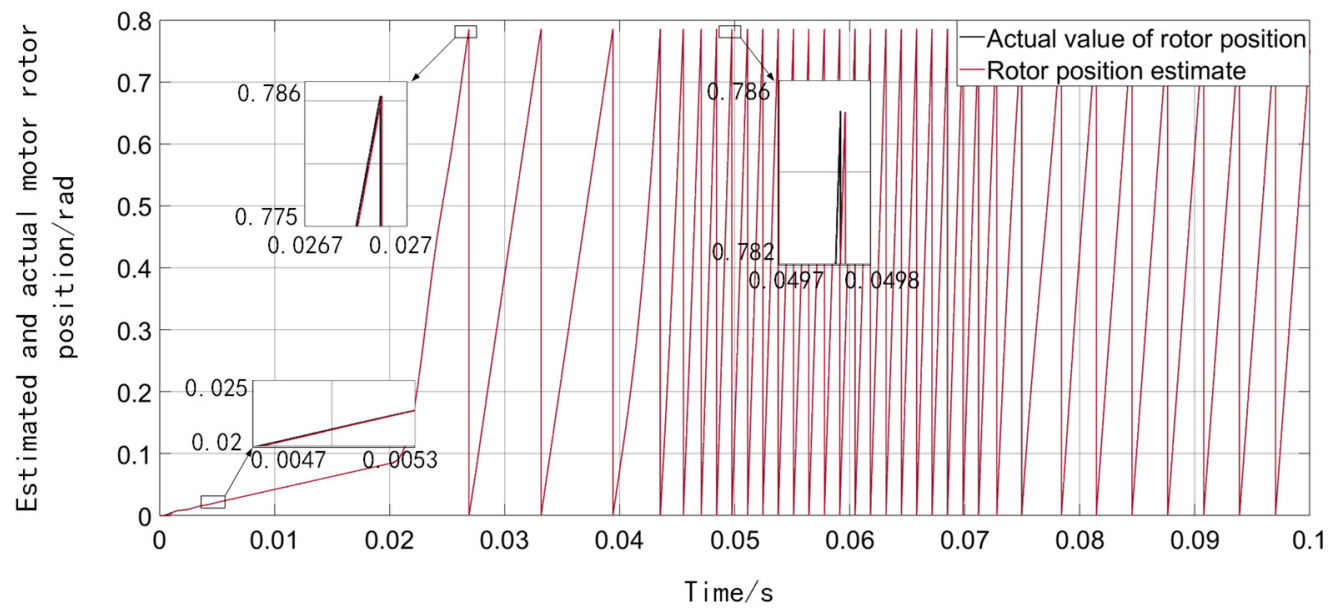

Figure 20. Comparison of the rotor position of the new improved SMO at full speed.

From Figures 19 and 20, the new and improved SMO based on the sigmoid function and the RLS adaptive filter can accurately estimate the motor speed and rotor position information at the full speed.

\section{Experimental Verification}

To verify the feasibility and practicability of the new improved SMO observer proposed in this paper, the new improved SMO observer was tested and verified with the aid of the experimental platform shown in Figure 21. The experiment part used the $150 \mathrm{~kW}$ simulation integrated equipment of Chongqing Dema Company, and the motor controller adopted the Renesas RH850 automotive-grade motor control chip that meets ISO26262 functional safety. The specific parameters of PMSM are as follows: rated voltage $350 \mathrm{~V}$, rated current $120 \mathrm{~A}$, rated power $25 \mathrm{~kW}$, rated torque $80 \mathrm{Nm}$, rated speed $3000 \mathrm{rpm}$, peak torque $175 \mathrm{Nm}$, peak speed $9000 \mathrm{rpm}$, peak power $55 \mathrm{~kW}$. 


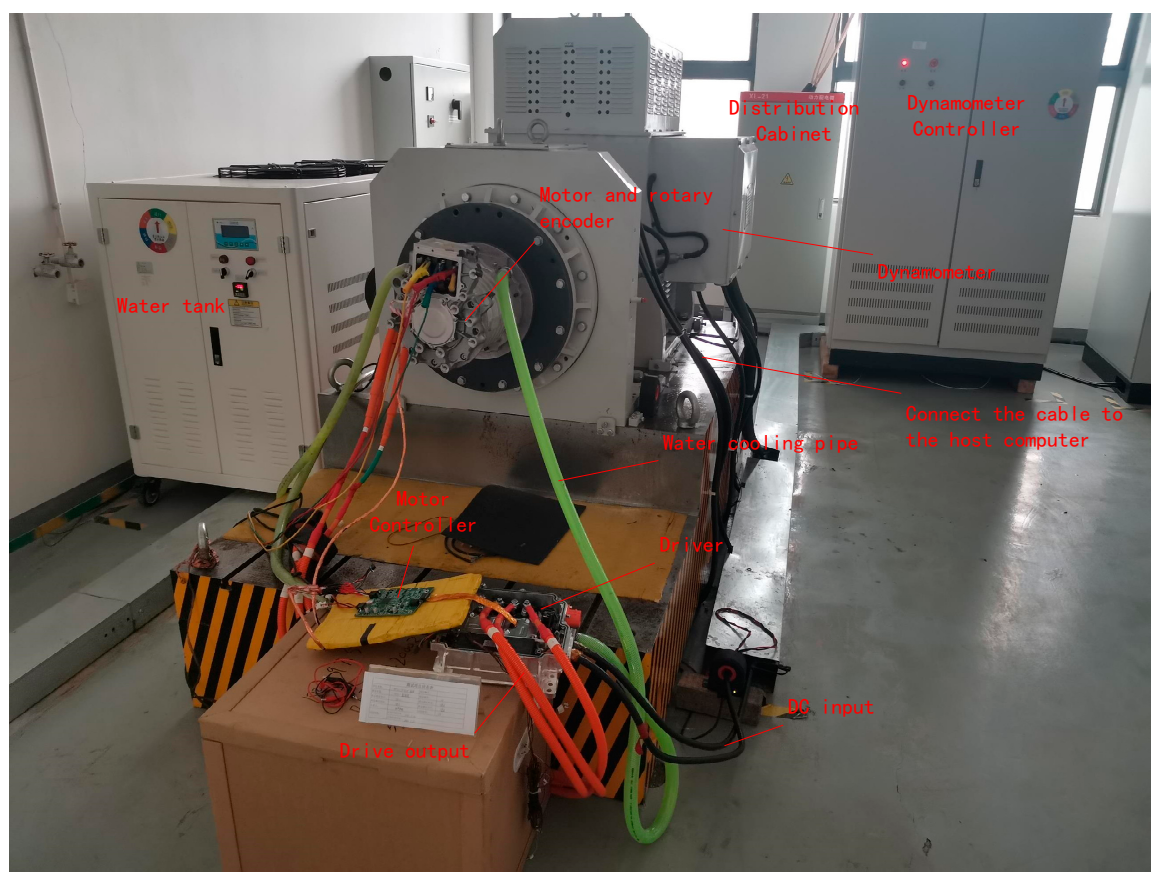

Figure 21. Experimental platform.

First, load the new improved SMO observer and the traditional SMO observer proposed in this paper into the motor controller respectively. After starting the device, the signal is transmitted through the Controller Area Network (CAN). The upper computer can receive the motor speed and rotor position information measured by the rotary encoder, as well as the motor speed estimated by the new and improved SMO observer. Rotor position information. The measured data detected by the rotary encoder are regarded as the real data. The feasibility of control strategy based on the new and improved SMO observer was verified by comparing the graphs of the estimated and measured data. In the experimental results, the unified yellow curve is the measured value of the motor speed, the blue curve is the estimated value of the motor speed, the red curve is the measured value of the motor rotor position, and the green curve is the estimated value of the motor rotor position.

Figure 22 is a graph comparing the actual and estimated values of the motor speed and rotor position based on the traditional SMO observer. The speed of the given motor is $50 \mathrm{rad} / \mathrm{s}$.

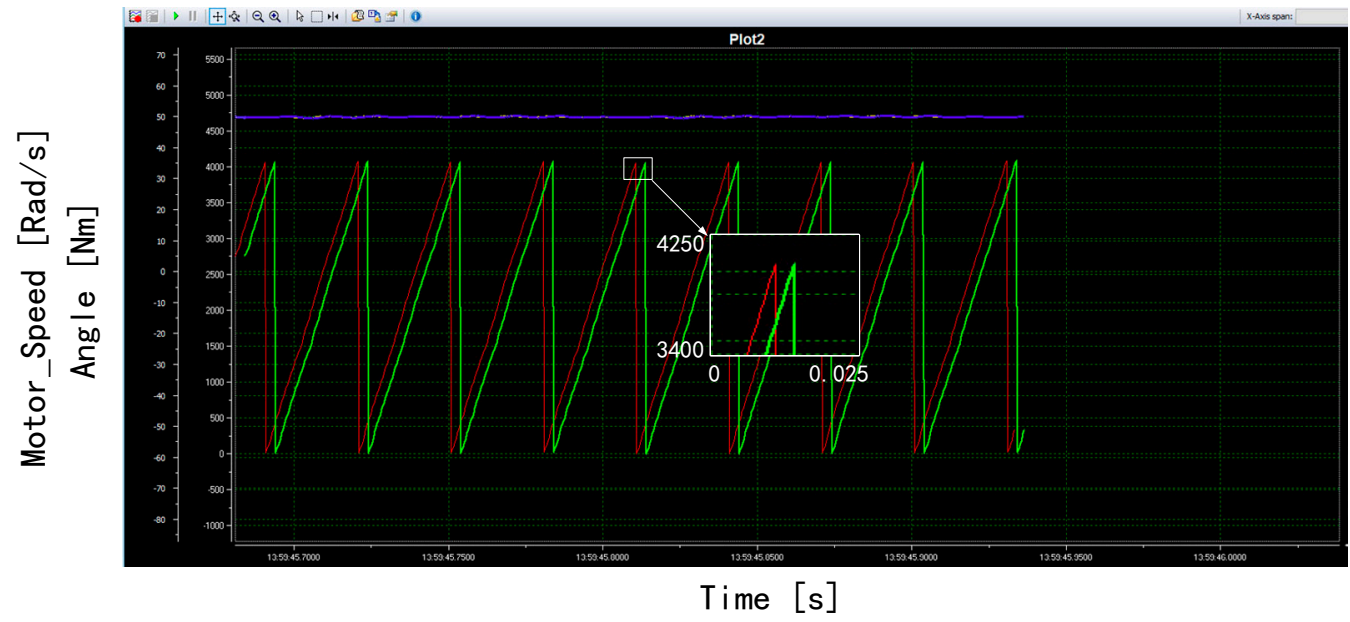

Figure 22. Comparison of motor speed and rotor position with the traditional SMO observer at $50 \mathrm{rad} / \mathrm{s}$. 
Figure 23 is a graph comparing the actual and estimated values of motor speed and rotor position based on the new and improved SMO observer. The speed of the given motor is $50 \mathrm{rad} / \mathrm{s}$.

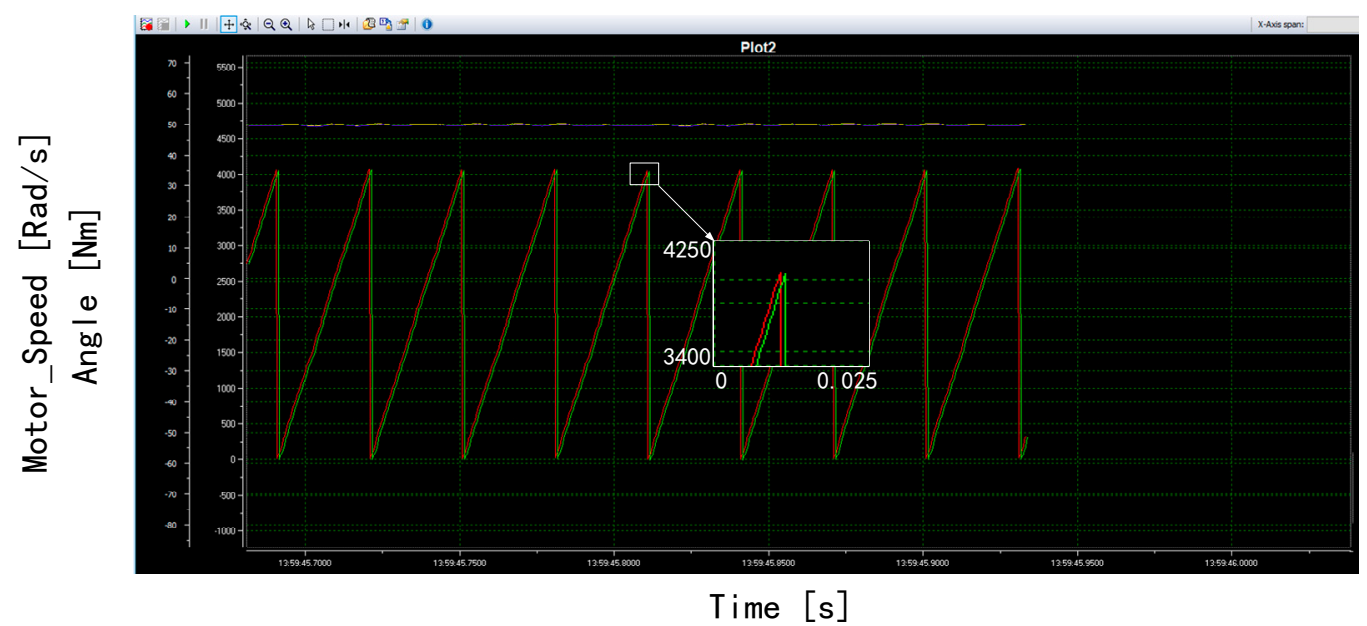

Figure 23. The comparison chart of the motor speed and rotor position of the new and improved SMO observer at $50 \mathrm{rad} / \mathrm{s}$.

Comparing the yellow and blue curves in Figure 23, the new and improved SMO observer has a higher estimation accuracy for the motor speed. Comparing the green and red curves, the new and improved SMO observer also has better estimation accuracy for the estimation of the motor rotor position.

Figure 24 is a graph comparing the actual and estimated values of motor speed and rotor position based on the new and improved SMO observer. The speed of the given motor is $100 \mathrm{rad} / \mathrm{s}$.

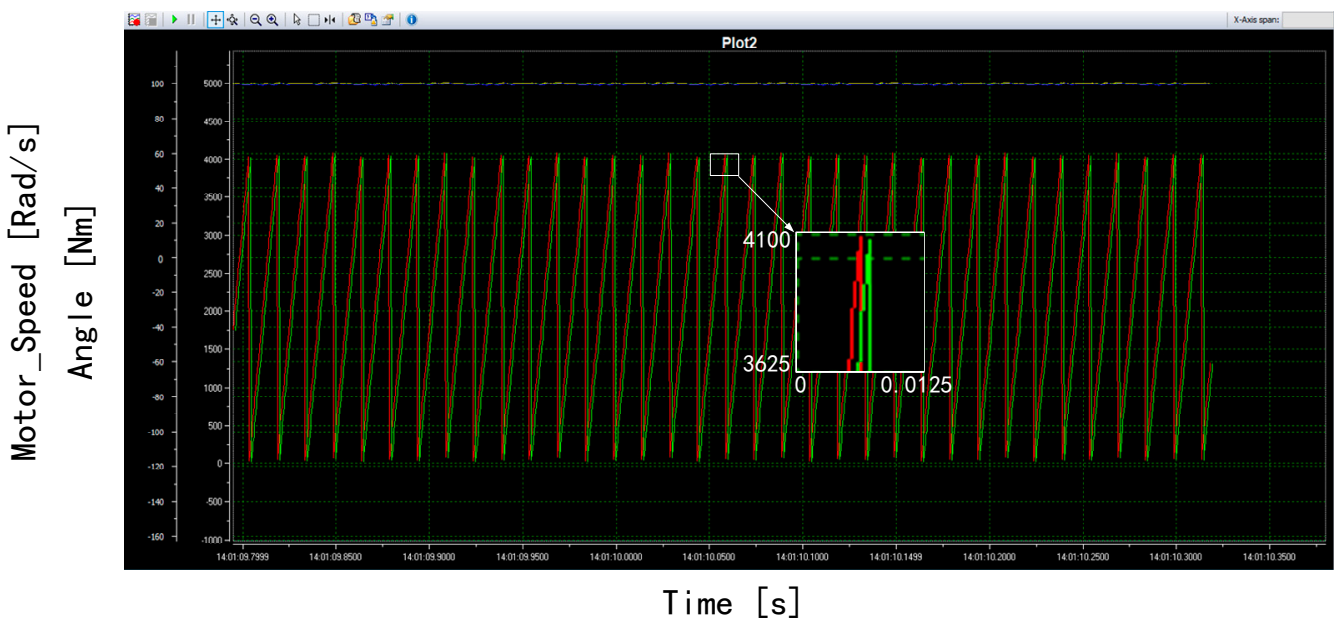

Figure 24. The comparison chart of the motor speed and rotor position of the new and improved SMO observer at $100 \mathrm{rad} / \mathrm{s}$.

Comparing the yellow and blue curves in Figure 24, the new and improved SMO observer has a higher estimation accuracy for the motor speed. Comparing the green and red curves, the new and improved SMO observer also has better estimation accuracy for the estimation of the motor rotor position.

Figure 25 is a graph comparing the actual and estimated values of motor speed and rotor position based on the new and improved SMO observer. The speed of the given motor is $200 \mathrm{rad} / \mathrm{s}$. 


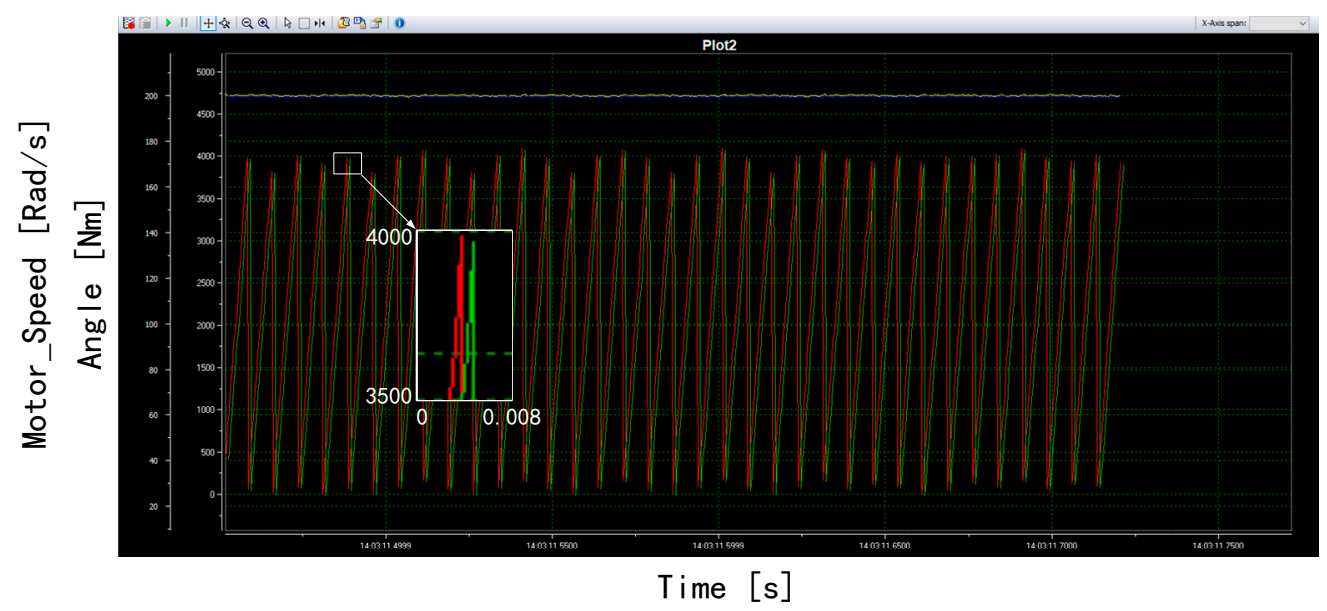

Figure 25. The comparison chart of the motor speed and rotor position of the new and improved SMO observer at $200 \mathrm{rad} / \mathrm{s}$.

Comparing the yellow and blue curves in Figure 25, it can be concluded that the new and improved SMO observer has a higher estimation accuracy for the motor speed. Comparing the green and red curves, the new and improved SMO observer also has better estimation accuracy for the estimation of the motor rotor position. Comparing Figures 22-25, when the motor is at $200 \mathrm{rad} / \mathrm{s}$, the rotor position angle of the motor is missing. This is because the CAN transmission cycle is slow when the motor speed is high, and the transmitted angle is intermittent.

\section{Conclusions}

This paper proposes an improvement strategy for the problems of high-frequency chattering, phase delay, low system convergence rate, and the inability to estimate the motor speed and rotor position in the low-speed section that exists in the traditional SMO control strategy of SPMSM. Simulation analysis and experiments verified the feasibility of the improved scheme. The sigmoid function was used to replace the signum function in the traditional synovial observer to achieve a system with smoother operation and faster convergence rate. Moreover, the high frequency chattering phenomenon of the system was greatly improved, and adaptive filtering with a variable cutoff frequency introduced. The filter replaces the low-pass filter to eliminate the harmonics and chattering and adaptively compensates the extracted electromotive force signal to improve the detection accuracy of the back electromotive force signal. In this way, the estimation error caused by the phase delay is reduced, the convergence rate of the synovial observer is further improved, and the synovial control strategy can also have a better observation effect in the low speed section. This method breaks the limitation that the sensor-less control strategy of the permanent magnet synchronous motor mostly uses the high frequency injection method at low speed. It also realizes a single sensor-less control strategy at full speed. However, compared with the traditional SMO, the new improved SMO increases the complexity of the operation, so the execution time will increase relatively. This problem needs to be considered in practical engineering applications. How to increase the operation rate of this method is very worthwhile, it is worth studying and improving further.

Author Contributions: Conceptualization, W.G. and G.Z.; methodology, W.G.; software, W.G., G.Z. and S.C.; validation, W.G., M.H. and P.L.; formal analysis, W.G. and G.Z.; investigation, W.G., M.H. and G.Z.; resources, W.G. and M.H.; data curation, W.G., S.C. and P.L.; writing-original draft preparation, W.G. and G.Z.; writing — review and editing, W.G. and G.Z.; visualization, W.G.; supervision, W.G.; project administration, W.G.; funding acquisition, W.G. All authors have read and agreed to the published version of the manuscript. 
Funding: This paper is partially supported by the Natural Science Foundation of Anhui Province (1908085MF215) and partially supported by Key Research and Development Project of Anhui Province (201904a05020007).

Conflicts of Interest: The authors declare no conflict of interest.

\section{References}

1. Dong, L.W. Study on sensorless stability control of motor for electric vehicle. Comput. Simul. 2017, 34, 182-186.

2. Choo, K.M.; Won, C.Y. Design and analysis of electrical braking torque limit trajectory for regenerative braking in electric vehicles with PMSM drive systems. IEEE Trans. Power Electron. 2020, 35, 13308-13321. [CrossRef]

3. Xu, Z.; Zhang, T.; Bao, Y.; Zhang, H.; Gerada, C. A nonlinear extended state observer for rotor position and speed estimation for sensorless IPMSM drives. IEEE Trans. Power Electron. 2019, 35, 733-743. [CrossRef]

4. Liu, J.L.; Xiao, F.; Shen, Y.; Mai, Z.Q.; Li, C.H.R. Position-sensorless control technology of permanent-magnet synchronous motor-a review. Trans. China Electrotech. Soc. 2017, 32, 76-88.

5. Cho, Y. Improved sensorless control of interior permanent magnet sensorless motors using an active damping control strategy. Energies 2016, 9, 135. [CrossRef]

6. Wang, S.; Yang, K.; Chen, K. An improved position-sensorless control method at low speed for PMSM based on high-frequency signal injection into a rotating reference frame. IEEE Access 2019, 7, 86510-86521. [CrossRef]

7. Zhu, Z.Q.; Gong, L.M. Investigation of effectiveness of sensorless operation in carrier signal injection based sensorless control methods. IEEE Trans. Ind. Electron. 2011, 58, 3431-3439. [CrossRef]

8. Wang, G.; Valla, M.I.; Solsona, J.A. Position sensorless permanent magnet synchronous machine drives-A review. IEEE Trans. Ind. Electron. 2019, 67, 5830-5842. [CrossRef]

9. Liu, B.; Zhou, B. Analysis and compensation of position estimation error in spmsm sensor-less control based on high frequency pulsating voltage injection. Proc. CSEE 2018, 38, 4232-4241, 4329.

10. Zhang, L.W.; Li, H.; Song, P.P.; Zhang, P.; Yun, L.S. Sensorless vector control using a new sliding mode observer for permanent magnet synchronous motor speed control system. Trans. China Electrotech. Soc. 2019, 34, 70-78.

11. Xu, W.; Qu, S.; Zhao, L.; Zhang, H. An improved adaptive sliding mode observer for middle- and high-speed rotor tracking. IEEE Trans. Power Electron. 2020, 36, 1043-1053. [CrossRef]

12. Chen, S.Y.; Pi, Y.G. Position sensorless control for permanent magnet synchronous motor based on sliding mode observer and sliding mode controller. Trans. China Electrotech. Soc. 2016, 31, 108-117.

13. Chen, S.Y.; Luo, Y.; Pi, Y.G. PMSM sensorless control with separate control strategies and smooth switch from low speed to high speed. ISA Trans. 2015, 58, 650-658. [CrossRef] [PubMed]

14. Foo, G.; Rahman, M.F. Sensorless sliding-mode MTPA control of an IPM synchronous motor drive using a sliding-mode observer and HF signal injection. IEEE Trans. Ind. Electron. 2010, 57, 1270-1278. [CrossRef]

15. Ye, S.; Yao, X. A modified flux sliding-mode observer for the sensorless control of PMSMs with online stator resistance and inductance estimation. IEEE Trans. Power Electron. 2020, 35, 8652-8662. [CrossRef]

16. Comanescu, M.; Xu, L. Sliding-mode MRAS speed estimators for sensorless vector control of induction Machine. IEEE Trans. Ind. Electron. 2006, 53, 146-153. [CrossRef]

17. Lin, M.; Li, Y.H.; Wu, C.H.; Yuan, G.Q.; Li, C.H. A model reference adaptive system based sliding mode observer for model predictive controlled permanent magnet synchronous motor drive. Trans. China Electrotech. Soc. 2017, 32, 156-163.

18. Zhang, M.; Xiao, X.; Li, Y.D. Speed and flux linkage observer for permanent magnet synchronous motor based on EKF. Proc. CSEE 2007, 27, 36-40.

19. Xu, D.; Zhang, S.; Liu, J. Very-low speed control of PMSM based on EKF estimation with closed loop optimized parameters. ISA Trans 2013, 52, 835-843. [CrossRef]

20. Silva, C.; Asher, G.M. Hybrid rotor position observer for wide speed-range sensorless PM motor drives including zero speed. IEEE Trans. Ind. Electron. 2006, 53, 373-378. [CrossRef]

21. Xue, Z.T.; Guo, Y.Y.; Li, Z.H. Estimation of permanent magnet synchronous motor rotor position for electric vehicle based on improved sliding mode observer. Mot. Control Appl. 2017, 44, 1-5, 39.

22. Kim, H.; Son, J. A high speed sliding mode observer for the sensorless speed control of a PMSM. IEEE Trans. Ind. Electron. 2011, $58,4069-4077$. 